\title{
Research on Customer Loyalty of O2O Takeout Logistics Service
}

\author{
SHAO, Mimi ${ }^{1}$, HUANG Yueyue. ${ }^{2,}$ * \\ ${ }^{1}$ School of Economics \& Trade, Xinhua College of Sun Yat-sen University; Guangzhou, Guangdong, China; \\ ${ }^{2}$ School of Foreign Languages, Xinhua College of Sun Yat-sen University; Guangzhou, Guangdong, China;
}

\begin{abstract}
With the wide-spread Internet, e-commerce has grown rapidly. It has prompted the traditional catering industry to form a novel "Internet plus catering" mode. In order to provide customers with costeffective products continuously, takeout platforms should focus more on high-quality consumer experience, so as to improve customer loyalty and occupy a larger market share. The paper attemps to prove that the customer loyalty can be improved by enhancing the quality of takeout $\mathrm{O} 2 \mathrm{O}$ logistics services. Through analysis of the status quo of takeout $\mathrm{O} 2 \mathrm{O}$ services and previous research conducted by other scholars, a comprehensive survey was conducted to collect basic data to constuct a measurement model of quality of $\mathrm{O} 2 \mathrm{O}$ logistics services. The result of this study suggests that: three factors seem to have a rather significant impact on customer loyalty, which are the timeliness, convenience and empathy for logistics services (impact degree in ascending order). It is hoped that this research can provide some insight for the development of food delivery industry.
\end{abstract}

\section{Introduction}

On June 2019, the 44th China Statistical Report on Internet Development released by the China Internet Network Information Centre (CCNIC) presented that China's online food delivery users had reached 421 million, an increase of 15.16 million from the end of 2018, and further growth in the future trend. Data from iMedia Research also suggests that the online food delivery industry is facing a new era of growth: the online food delivery market is expanding in third- and fourth-tier cities; beauty products, baby products and pharmaceutical products are among the most popular categories for online retail delivery services; finally, we are entering a new consumption era - as GDP and other economic indicators of China showing a strong growing momentum, consumption structure has been upgraded as people's views on consumption have begun to change, and some have begun to accept takeaways with higher prices. Since the fourth quarter of 2018, the proportion of each order with a price higher than 40 yuan has reached $32.9 \%$.

Therefore, if a $\mathrm{O} 2 \mathrm{O}$ food delivery platform desires to stand out in the fierce competition and remain a evergowing momentum, it must devote enough value on keeping its consumers loyal. To achieve such a goal, the platform must provide high-quality service to improve consumer satisfaction. By providing decent food with proper price and reliable service, it thus can uphold its fundamental competitiveness.

Traditionally, food delivery $\mathrm{O} 2 \mathrm{O}$ platforms enter the industry by subsidizing users. This method can increase the order volume to a certain extent, but it also lead to a decline in profits, and a further decrease in service quality or a drop in food quality. Maintaining customers loyal become difficult under such conditions. Thus, on the contrary, in order to boost customer loyalty and aquire larger market share, food delivery platforms need to continue to provide customers with cost-effective products, and lay emphasis on improving consumer experience. In addition, since customers' most intuitive impression is on the quality of delivery service, it will then directly affect the consumers' experience as well.

Previous studies on customer loyalty in the ecommerce industry mostly centre on $\mathrm{O} 2 \mathrm{O}$ business models and industry applications, and relatively few have touched upon the theoretical discussion on $\mathrm{O} 2 \mathrm{O}$ food delivery logistics services. Therefore, by referring to the relevant literature in this field and analysing the data collected, this paper intends to expand research by focusing on customer loyalty of the $\mathrm{O} 2 \mathrm{O}$ food delivery platform. In terms of the quality of logistics services in the food delivery industry, this article proposes to boost customer loyalty by improving the quality of $\mathrm{O} 2 \mathrm{O}$ logistics services, which, hopefully, can help the longterm development of the companies in the industry.

\section{Theoretical Framework}

\subsection{Quality of Logistics Services}

Mentzer, Gomes and Krapfe (1989) proposed two layers of quality of logistics service-marketing services for customers and distribution services on logistics, and three indicators for logistics distribution - usability, timeliness and quality. In China, regarding logistics service quality, scholars also have their own views: Wang (2015) believed

*Corresponding Author: Email: flhuangyueyue@xhsysu.edu.cn 
that due to the particularity of catering trade, logistics and distribution were the core of the competition for $\mathrm{O} 2 \mathrm{O}$ food-delivery platforms. Chen et al. (2016) concluded that service quality was rather influencial among several factors affecting customer satisfaction. Ding and Zheng (2018) then further suggested that logistics companies should take the initiative to conduct surveys on customer satisfaction, and, based on that, to improve their service quality in order to better cope with the market volatility to survive and grow.

Regarding the measurement model of logistics service quality, in the late 1980s, Parasuraman, Zeithaml, and Berry (1988) proposed a SERVQUAL model, containing a total of five indicators for service quality assessment, i.e. tangibility, reliability, responsiveness, security and empathy. Then a further research conducted by Tennessee University in 2001 presented a more complete explanation on the overall quality of logistics services, called LSQ scale, including 9 dimensions (See Figure 1).

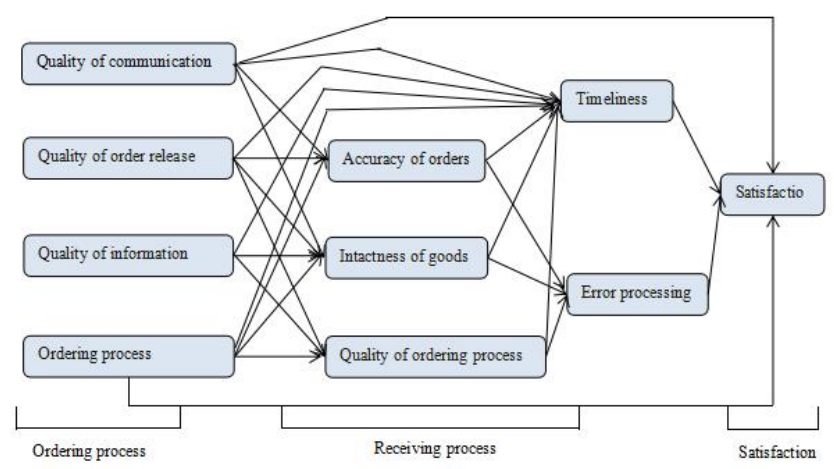

Figure 1- LSQ model

Based on the above model, Zheng (2008) concluded that the logistics quality of $\mathrm{B} 2 \mathrm{C}$ online store should include five measurements: quality of order, quality of personalized service, quality of order response, and time of payment and quality of errors response. Combining the needs of Chinese consumers, Guan (2015) further summarized five dimensions of B2C online store logistics services: timeliness, reliability, safeness and responsiveness. In summarization, logistics service quality plays an increasingly important role in the development of $\mathrm{B} 2 \mathrm{C}$ e-commerce and will gradually become the core of competitiveness (Li and Sun, 2017).

\subsection{Customer Loyalty}

Substantial progress has been made on research on customer loyalty so far. Ma (2003) concluded that loyalty of customers meant that they would place more and more reliance on specific companies, or the products and services provided by that companies or brands. Special preferences will then be formed, and they will become frequent customers, and, actively and initiatively, will recommend their favorates to others. Ren (2009) believed that this loyalty led customers to maintain a close relationship with specific companies, and to resist other counterparts. Under the online shopping environment, Lin (2015) analyzed the relationship between the logistics service quality and customer loyalty, and found that a higher perceived satistisfaction with unfailing punctuality, smooth communication, resonable pricing, convenient ordering process, intact delivery, and quick response to errors and to logistics information can lead to higher loyalty to the B2C online store. Xue et al. (2017) further pointed out that, among all the factors influencing customers' perceptions, three factors (logistical operation capability, logistical information capability, and logistics factor capability) all have a positive correlation with customer value. Based on the aforementioned research, it is clear to find the irreplaceable value of logistics services for customers.

\subsection{Hypothesis}

Through analysis of characteristics in food delivery industry and factors in its distribution process, this paper establishes a model attempting to measure the relationship between the quality of logistics services and customer loyalty in the industry. The model adopts five dimensions for the measurement of quality of logistics services, i.e. timeliness, reliability, convenience, responsiveness, and empathy, which are explained as follows:

(1) Since customers normally choose takeouts only for convenience and for a quick solution of lunch, the delivery service thus must have higher requirement for punctuality. If the food is delivered too late, disatisfied customers naturally will have negative impression on takeaway platforms or merchants, and may even pulled them into "blacklist." Therefore, "timeliness" is an important indicator for this measurement. It is measured as whether orders can be received in a timely manner, whether the order can be delivered on time, and whether the return service can be processed timely.

Hypothesis 1(H1): The timeliness of logistics services has a positive correlation with customer loyalty.

(2) When an order contains varied types of foods and some are difficult to be packed, compared with other ecommerce logistics, customers of this kind prefer to receive their food intact within a limited period of time after ordering. Therefore, "reliability" comes with the needs in the $\mathrm{O} 2 \mathrm{O}$ catering industry, and it is certainly an indicator for evaluation of takeaway platforms. It can be further sub-divided into several secondary metrics: whether the number of and types of foods delivered are accurate; whether the delivered items are intact; whether the staff can successfully deliver the takeouts within the agreed time.

Hypothesis 2 (H2): Reliability of logistics service has a positive correlation with customer loyalty.

(3) Compared with traditional catering industry, apart from the convenience for food ordering, there will be a greater desire for customers of online food delivery services to know the right-to-the-point status of their delivery. "Convenience" thus is examined by whether customers can select their preferred delivery time, whether they can easily change it if placing wrong orders, whether they can change their ordering information, and whether they can easily check out the real-time status of their orders.

Hypothesis 3 (H3): Convenience of logistics services has a postive correlation with customer loyalty. 
(4) For customers of the $\mathrm{O} 2 \mathrm{O}$ industry, it is very vital for them to receive the information provided by the platform or to send the information to the platform from the time of order to the receipt. Therefore, the metric of "responsiveness" in this paper will be measured by whether the logistics information provided by the platform is accurate; whether it can correctly handle the problems from customers; and whether it can properly handle the customers'cancelled orders.

Hypothesis 4 (H4): Responsiveness of logistics service has a postive correlation with customer loyalty.

(5) In food delivery industry, the only direct contact between the platforms and customers is often through delivery personnels who can provide customized services. Their behavior and response is thus an important indicator for customers to evaluate the quality of take-out logistics services. Therefore, in this paper, the metric of "empathy" will be further measured by whether delivery staffs are properly dressed and behave, whether they treat customers gently, and whether they can respond to customers'specific needs, such as asking no calls instead of sending text messages when delivering.

Hypothesis 5 (H5): The empathy of logistics services has a postive correlation with customer loyalty.

The research model then is illustrated as follows (Figure 2):

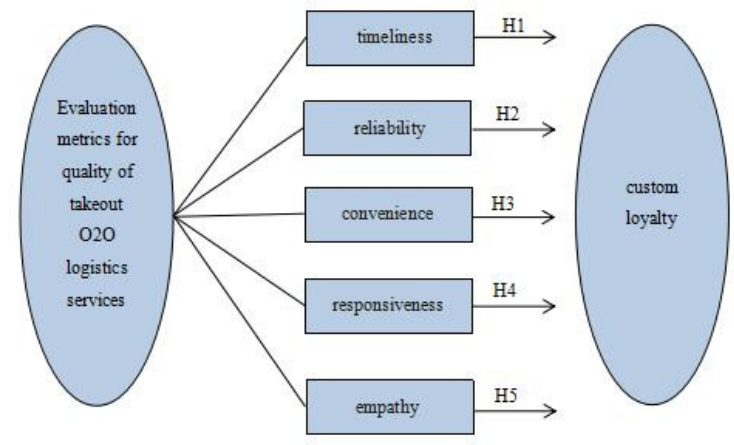

Figure 2-Measurement model for customer loyalty in food delivery $\mathrm{O} 2 \mathrm{O}$ logistics service quality

\subsection{Research Design}

Following random principles, a questionnaire for this survey was created on "Wenjuanxing", an online survey platform, and then was distributed for data collection. Participants for this survey must have online food ordering experience and have a certain understanding of the $\mathrm{O} 2 \mathrm{O}$ takeout industry. As a result, a total of 235 questionnaires were collected, and 228 were valid.

Descriptive statistical analysis of those valid questionnaires indicates that the gender ratio of respondents was $40.79 \%$ for men and $67.5 \%$ for women, and that their professions were taken up by $63.6 \%$ of students, $4.39 \%$ of teachers, $25 \%$ of company employees and private employers, and $7.02 \%$ of other occupations. As for the platfoms that they used, $39.47 \%$ votes for "Meituan Takeout", 5.26\% for "Koubei Takeout", 47.37\% for "Ele.me", $2.63 \%$ for "Baidu takeout", and $5.26 \%$ placed orders on other food ordering websites. The proportion of users who order meals once a month is $21.06 \%$, while the proportion of respondents who order meals multiple times a week on the takeaway platform is as high as $48.68 \%$, and only $23.68 \%$ of users who consume more than 300 meals per month.

The questionnaire includes five metrics fo quality of logistics services: timeliness, reliability, convenience, responsiveness, and empathy. A 5 Likert scale was adopted to add ease for respondents' evaluation and for the researcher to assess the scale.

\section{Data Analysis}

\subsection{Reliability Analysis}

Cronbach's alpha was adopted to measure the reliability of the questionnaire. When $\alpha$ is greater than 0.8 , the confidence level is good; between 0.7 and 0.8 , it is reasonable; between 0.6 and 0.7 , it is acceptable but needs to be improved. SPSS19.0 was used to analyze the reliability of each metric in the questionnaire as shown in Table 1. As can be seen in Table 1, the Cronbach coefficient for most metrics exceeds 0.8, except for timeliness $(=.794)$, indicating a rather high consistancy within this questionnaire. It suggests that this questionnaire can be used as a reliable tool for this study.

Table 1 Results of reliability analysis for each metric

\begin{tabular}{l|ll}
\hline Metrics & $\begin{array}{l}\text { No. of items } \\
\text { measured }\end{array}$ & Creditability \\
\hline $\begin{array}{l}\text { Timeliness for } \\
\text { logistics service } \\
\text { Reliability for logistics } \\
\text { service }\end{array}$ & 3 & .794 \\
$\begin{array}{l}\text { Convenience for } \\
\text { logistics service }\end{array}$ & 3 & .839 \\
$\begin{array}{l}\text { Responsiveness for } \\
\text { logistics service } \\
\text { Empathy for logistics } \\
\text { service } \\
\text { Customer loyalty }\end{array}$ & 3 & .819 \\
\hline
\end{tabular}

\subsection{Correlation Analysis}

The results of the correlation analysis of the variables are shown in Table 2. As each correlation data returns postive and its significance level does not exceed 0.01 , indicating a significant and positive correlation between customer loyalty and each metrics.

Table 2 Correlation analysis

\begin{tabular}{|c|c|c|c|c|}
\hline & & $\begin{array}{l}\text { logistics } \\
\text { service } \\
\text { timeliness }\end{array}$ & $\begin{array}{c}\text { logistics } \\
\text { service } \\
\text { reliabilit } \\
y\end{array}$ & $\begin{array}{c}\text { logistics } \\
\text { service } \\
\text { convenienc } \\
\text { e }\end{array}$ \\
\hline \multirow{4}{*}{$\begin{array}{l}\text { Custome } \\
\text { r loyalty }\end{array}$} & $\begin{array}{c}\text { Pearson } \\
\text { Correlatio } \\
n\end{array}$ & $.611 * *$ & $.564 * *$ & $.639 * *$ \\
\hline & $\begin{array}{l}\text { Sig. (2- } \\
\text { sided) }\end{array}$ & .000 & .000 & .000 \\
\hline & $N$ & 228 & 228 & 228 \\
\hline & & $\begin{array}{c}\text { logistics } \\
\text { service } \\
\text { responsivene } \\
\text { ss }\end{array}$ & $\begin{array}{l}\text { logistics } \\
\text { service } \\
\text { empathy }\end{array}$ & \\
\hline
\end{tabular}




\begin{tabular}{|c|c|c|c|}
\hline \multirow{3}{*}{$\begin{array}{l}\text { Custome } \\
\text { r loyalty }\end{array}$} & $\begin{array}{c}\text { Pearson } \\
\text { Correlatio } \\
n\end{array}$ & $.676 * *$ & $.727 * *$ \\
\hline & $\begin{array}{l}\text { Sig. (2- } \\
\text { sided) }\end{array}$ & . 000. & .000 \\
\hline & $N$ & 228 & 228 \\
\hline
\end{tabular}

\subsection{Regression Analysis}

In this study, customer loyalty was set as dependent variable, and metrics of timeliness, reliability, convenience, feedback and empathy were then as independent variables; multiple linear regression analysis was then conducted with stepwise mode.

Table 3 Results of multiple linear regression analysis

\begin{tabular}{c|cccc}
\hline Model & R & R2 & $\begin{array}{c}\text { Adjusted } \\
\text { R2 }\end{array}$ & $\begin{array}{c}\text { Std. Error of the } \\
\text { Estimate }\end{array}$ \\
\hline 1 & $.727 \mathrm{a}$ & .529 & .527 & .54338 \\
2 & $.752 \mathrm{~b}$ & .565 & .561 & .52326 \\
3 & $.760 \mathrm{c}$ & .577 & .572 & .51718 \\
\hline
\end{tabular}

The above table reflects a goodness of fit for model 3 (Adjusted R2=.572).

Table 4 ANOVA test

\begin{tabular}{c|c|ccccc}
\hline \multicolumn{2}{c}{ Model } & $\begin{array}{c}\text { Sum of } \\
\text { Squares }\end{array}$ & df & $\begin{array}{c}\text { M. } \\
\text { Square }\end{array}$ & F & Sig. \\
\hline 1 & Regression & 74.993 & 1 & 74.993 & 253.984 & $.000 \mathrm{a}$ \\
& Residual & 66.730 & 226 & .295 & & \\
& Total & 141.723 & 227 & & & \\
\cline { 2 - 7 } 2 & Regression & 80.118 & 2 & 40.059 & 146.305 & $.000 \mathrm{~b}$ \\
& Residual & 61.606 & 225 & .274 & & \\
& Total & 141.723 & 227 & & & \\
\cline { 2 - 7 } 3 & Regression & 81.808 & 3 & 27.269 & 101.950 & $.000 \mathrm{c}$ \\
& Residual & 59.915 & 224 & .267 & & \\
& Total & 141.723 & 227 & & & \\
\hline
\end{tabular}

The above table suggests its model 3 is significant in the overall sense $(\mathrm{F}=101.950, \mathrm{p}=0.000<0.05)$.

Table 5 Coefficients results

\begin{tabular}{ccccccc}
\hline \multirow{2}{*}{ Model } & \multicolumn{2}{c}{$\begin{array}{c}\text { Unstandardized } \\
\text { Coefficients }\end{array}$} & $\begin{array}{c}\text { Standardized } \\
\text { Coefficients }\end{array}$ & & Sig. \\
\cline { 2 - 4 } & $\mathbf{B}$ & $\begin{array}{c}\text { Std. } \\
\text { Error }\end{array}$ & Beta & & \\
\hline 3 & .290 & .207 & & 1.400 & .163 \\
\hline $\begin{array}{c}\text { (Constant) } \\
\begin{array}{c}\text { Empathy of } \\
\text { logistics } \\
\text { service }\end{array}\end{array}$ & .519 & .068 & .488 & 7.598 & .000 \\
$\begin{array}{c}\text { Convenience } \\
\text { of logistics } \\
\text { service }\end{array}$ & .196 & .065 & .196 & 2.995 & .003 \\
\hline $\begin{array}{c}\text { Timeliness of } \\
\text { logistics } \\
\text { service }\end{array}$ & .178 & .071 & .158 & 2.514 & .013 \\
\hline
\end{tabular}

Using stepwise mode, regression analysis returns two metrics, reliability and responsiveness, with p-value greater than 0.05 , thus they were excluded in Table 5. The remaining three variables have a significant effect on the dependent variable (customer loyalty). For empathy, its regression coefficient equals 0.519 and its p-value is 0.000 $(<0.05)$, indicating that it has a positive and significant effect on customer loyalty. Customers who demonstrate greater empathy towards logistics service show higher loyalty with the brands. For convenience, regression coefficient is 0.196 with a p-value of $0.003(<0.05)$, suggesting a significant and positive impact on customer loyalty. Thus, the more satisfied customers are with the convenience of logistics services, the more loyal customers are. For timeliness, it is 0.178 with a p-value of $0.013(<0.05)$, also indicating a significance positive effect. In other words, customers with higher satisfaction on the timeliness of logistics services will show higher loyalty. Combined all three variable constants, i.e. empathy, convenience, and timeliness, in this model using unstandardized coefficients, the following equation then can be composed:

Customer loyalty $=0.519 *$ empathy of logistics service $+0.196 *$ convenience of logistics service +0.178 $*$ timeliness of logistics service +0.29

From the above equation obtained from the study, it can suggest that the logistics service quality of $\mathrm{O} 2 \mathrm{O}$ food delivery has a positive impact on customer loyalty, of which the degree of influence from small to large are timeliness, convenience, and empathy.

\subsection{Test of Hypothesis}

Based on the regression analysis obtained from the study, the resulting validation of each hypothesis is summarized in Table 6.

Table 6 Regression hypothesis

\begin{tabular}{l|l}
\hline Hypothesis & $\begin{array}{l}\text { Test } \\
\text { result }\end{array}$ \\
\hline H1: The timeliness of logistics services has a & Acce \\
positive correlation with customer loyalty. & pted \\
H2: Reliability of logistics service has a positive & Rejec \\
correlation with customer loyalty. & ted \\
H3: Convenience of logistics service has a positive & Acce \\
correlation with customer loyalty. & pted \\
H4: Responsiveness of logistics service has a & Rejec \\
positive correlation with customer loyalty. & ted \\
H5: Empathy of logistics services has a positive & Acce \\
correlation with customer loyalty. & pted \\
\hline
\end{tabular}

\subsection{Revised Model}

After empirical analysis, our findings have led to a final model with the following regression equations:

Customer loyalty $=0.519 *$ empathy of logistics service $+0.196 *$ convenience of logistics service $+0.178 *$ timeliness of logistics service +0.29

The model of this study is then modified according to the variables and coefficients of the equation as follows:

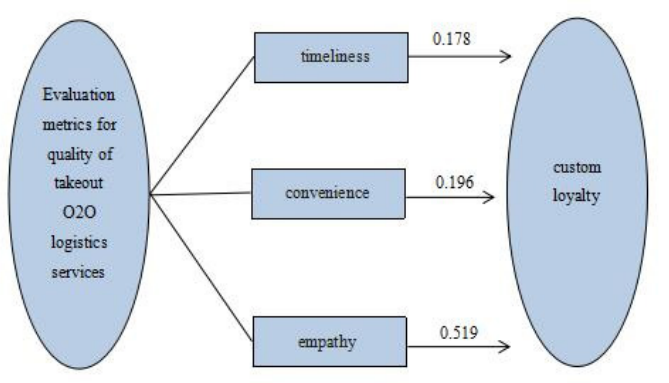

Figure 3- Model of impacting metrics of logistics service quality on customer loyalty in food delivery $\mathrm{O} 2 \mathrm{O}$ industry 


\section{Conclusion and Suggestion}

This paper attempts to study the degree of influence of various factors for the logistics service quality on customer loyalty in takeaway $\mathrm{O} 2 \mathrm{O}$ industry, to analyse and study customer loyalty for takeaway platforms, and to make reasonable suggestions to improve the quality of logistics service.

The study first can indicate that, as the unstandardized coefficients for timeliness and convenience are 0.178 and 0.196 respectively, impact of convenience for logistics on customer loyalty is greater than its timeliness. Compared with traditional catering, customers in food delivery industry prefer to have a faster and more convenient ordering platform. Timeliness and convenience are, therefore, rather important factor in increasing customer loyalty. Moreover, the unstandardized regression coefficient of the logistics of empathy on customer loyalty is 0.519 , indicating an even greater impact compared with timeliness and convenience. It can be infered that since delivery staffs are the ones who comes into direct contact with customers during food delivery, their image, etiquette, and the way they treat users are all very important, so how the platform effectively manages their service quality will affect the customer loyalty to a large extent.

Therefore, the very first suggestion for food delivery platforms to obtain customer loyalty is to enhance efficiency of their delivery services. As timeliness being a rather influential factor with customer loyalty, the platforms should further improve their services on accepting and delivering orders, and processing return orders. What take-out users are looking for is fast speed, so an efficient logistics system can attract and retain more users, obtaining higher profits. Secondly, system for food delivery platforms needs to be further improved. The platforms should focus on their improvement of "convenience" to simplify the ordering process and speed up the status updates so as to ensure that users can complete orders in the shortest possible time. Finally, it is also very important to enhance the service quality of their delivery staff, as customers not only require fine dining experience, but also need to receive first-hand service by the staff. Therefore, it is necessary to strengthen the training of the delivery staff and standardize the delivery system, so that customers have a better experience. It is then that their favours for the specific takeout platform can be gained and their high loyalty will be maintained to that platform.

\section{Acknowledgement}

This paper is the phased achievement of Higher Education Reform Project of Guangdong Province (2018J051): International Trade Course Reform under the New Format-Based on the "Cross-border E-commerce Entrepreneurship" Perspective; Humanities and Social Sciences Project of Guangdong Higher Educational Schools (2017WQNCX158): Research on the impact of incentive supervision in crowdfunding platforms on the sponsors' strategic behaviours.

\section{References}

1. China Internet Network Information Centre, (CCNIC), the 44th China Statistical Report on Internet Development,2019.

2. iiMedia Research, 2018-2019 China Online Take-out Industry Analysis Report,2019.

3. Zeithaml V A, Varadarajan P, Zeithaml C P. "The Contingency Approach: Its Foundations and Relevance to Theory Building and Research in Marketing" [J]. European Journal of Marketing, 1988,22(7): 37-64.

4. Mentzer J T, Flint D J, Kent J L. "Developing a logistics service quality. Scale. Journal of Business Logistics" [J], 1999,20(1): 9-32.

5. Lin, Liming. "Research on Relationship between B2C E-commerce Logistics Service Quality and Customer Loyalty. Logistics Engineering and Management" [J]. 2015,37(06): 129-131.

6. Zheng, Bing. A Study on Logistics Service Quality and Its Relationship with Customer Loyalty of B2C Internet. Doctoral Thesis, Dalian University of Technology.2008.

7. Wang, Yanjie. "Study on Logistics Strategies under Takeout O2O Market. Logistics Technology" [J].2015, 34(10): 17-19. 